\title{
Characterization of Acr2, an H-NS-like protein encoded on A/C2-type plasmids
}

\author{
Kevin S. Lang ${ }^{1}$ and Timothy J. Johnson ${ }^{1}$ \\ ${ }^{1}$ University of Minnesota \\ Department of Veterinary and Biomedical Sciences \\ St. Paul, MN 55108
}

\section{Correspondence:}

Timothy J. Johnson, University of Minnesota, Department of Veterinary and Biomedical Sciences, 1971 Commonwealth Ave, St. Paul, MN 55108. Tel: (612) 626-2542 Fax: (612)625-5203 Email: joh04207@umn.edu

\footnotetext{
Abstract

(C) 2016. This manuscript version is made available under the Elsevier user license http://www.elsevier.com/open-access/userlicense/1.0/
} 
Conjugation plays an important role in the horizontal movement of DNA between bacterial species and even genera. Large conjugative plasmids in Gram-negative bacteria are associated with multi-drug resistance and have been implicated in the spread of these phenotypes to pathogenic organisms. A/C plasmids often carry genes that confer resistance to multiple classes of antibiotics. Recently, transcription factors were characterized that regulate $\mathrm{A} / \mathrm{C}$ conjugation. In this work, we expanded the regulon of the negative regulator Acr2. We developed an A/C variant, pARK01, by precise removal of resistance genes carried by the plasmid in order to make it more genetically tractable. Using pARK01, we conducted RNA-Seq and ChAP-Seq experiments to characterize the regulon of Acr2, an H-NS-like protein. We found that Acr2 binds several loci on the plasmid. We showed, in vitro, that Acr2 can bind specific promoter regions directly and identify key amino acids which are important for this binding. This study further characterizes Acr2 and suggests its role in modulating gene expression of multiple plasmid and chromosomal loci.

\section{INTRODUCTION}

The IncA/C plasmid type has spread globally and is now a major contributor to multidrug 
resistance in enteric pathogens (1-4). This plasmid type is modular in nature, containing several variable regions encoding antimicrobial resistance mechanisms and a conserved backbone of core genes for plasmid replication and maintenance $(2,4-6)$. Recent work characterized several transcriptional regulators encoded by the core backbone (7). These regulators were found to regulate conjugative transfer of IncA/C plasmids. Interestingly, one of the negative regulators, Acr2, is similar to H-NS, a chromosomally encoded, global transcriptional regulator (2).

There are several nucleoid-associated proteins encoded by E. coli. H-NS is among the most well studied (8). H-NS binds preferentially to DNA with a low G $+\mathrm{C}$ content (9). These sequences serve as sites of initial binding. After these initial interactions, other copies of H-NS can bind to each other via protein-protein interactions, as well as the DNA, forming large complexes $(9,10)$. This is achieved through two distinct domains. The N-terminus of H-NS contains a oligomerization domain and the C-terminus contains a DNA binding domain (11). Primarily, H-NS binding results in silencing of adjacent gene transcription $(12,13)$.

Chromosomal copies of H-NS play an important role in regulation of horizontally acquired DNA, such as pathogenicity islands (14-16). In some cases, mobile elements encode their own copies of H-NS homologs (17-19). These horizontally encoded homologs of H-NS have been shown to antagonize the binding of the chromosomal copies of H-NS to horizontally acquired DNA $(13,20)$. These antagonistic H-NS homologs have been found only on genomic islands of pathogenic E. coli, which is 
intuitive, given their specific function. There have been a few studies focusing on plasmid encoded H-NS homologs $(17,18,21,22)$. H-NS homologs from plasmid pSfR27 and pCAR (Sfh and Pmr, respectively) seem to play roles in regulating a diverse set of genes, some of which are regulated by the chromosomally encoded H-NS copies $(17,18$, 22). It has been proposed that uncontrolled expression of these genes, caused by plasmid acquisition, could lead to a reduction in fitness and subsequent loss of the plasmid from the population. The H-NS homolog encoded on the R27 plasmid of E. coli, $\mathrm{H}_{-\mathrm{NS}} \mathrm{R}_{\mathrm{R} 7}$, has been shown to directly interact with the plasmid's origin of replication, oriT and other transfer associated genes to regulate conjugation (21). $\mathrm{H}-\mathrm{NS}_{\mathrm{R} 27}$ was shown to be involved in an intricate interplay of chromosomally encoded H-NS homologs to thermally regulate the expression of the conjugative transfer apparatus of R27. These recent studies exemplify the diverse roles these plasmid encoded H-NS homologs serve. Given how widely distributed these homologs are amongst plasmid types, the true diversity of roles for H-NS homologs is unknown (23).

In this study, we characterize Acr2, an H-NS-like protein that was found to negatively regulate conjugative transfer. RNA-Seq and ChAP-Seq (Chromatin Affinity Precipitation-Seq) were used to characterize Acr2 binding sites and regulatory network. We show that Acr2 binds multiple loci on the plasmid, specifically in regions of transfer genes and transposons carried by the plasmid. Additionally, we found that Acr2 binds several loci on the host bacterial chromosome and may directly alter host gene expression. Our sequence analysis indicates that Acr2 shares a DNA binding motif with that of other H-NS homologs and using site-directed mutagenesis we demonstrate that 
these amino acids are critical for its function as a repressor of conjugation.

\section{MATERIALS AND METHODS}

\subsection{Bacterial strains, plasmids and growth conditions.}

The bacterial strains and plasmids are listed in Table 1. All strains were routinely grown in Difco ${ }^{\mathrm{TM}}$ Luria-Bertani (LB) broth or LB agar at $37^{\circ} \mathrm{C}$ unless otherwise noted. Broth cultures were grown in a shaking incubator at $37^{\circ} \mathrm{C}$ with shaking (200 RPM) unless otherwise noted. Supplementation of ampicillin (Amp, $100 \mu \mathrm{g} / \mathrm{mL}$ ), chloramphenicol (Cm, $20 \mu \mathrm{g} / \mathrm{mL})$, nalidixic acid (Nal, $30 \mu \mathrm{g} / \mathrm{mL})$, kanamycin (Kan, $100 \mu \mathrm{g} / \mathrm{mL}$ ), rifampicin (Rif, $100 \mu \mathrm{g} / \mathrm{mL}$ ) and tetracycline $(12.5 \mu \mathrm{g} / \mathrm{mL})$ were used as needed. Counter-selections were done using M9 minimal agar was supplemented with $0.2 \%$ rhamnose. Arabinose induction of pBAD22 vector constructs was achieved with a final concentration of $0.02 \%$. X-gal was added to agar plates at a concentration of $40 \mu \mathrm{g} / \mathrm{mL}$. Diaminopimelic acid (DAP) was add to a final concentration of $300 \mu \mathrm{M}$ to facilitate growth of WM3064.

\subsection{Strain construction via recombineering.}

All deletions and mutations were done via $\lambda$-Red mediated recombination (recombineering) with some variations. In order to delete the resistance genes from pAR060302, strain DY331 was used because it expresses recombineering genes from the chromosome and not from a plasmid which must be selected for. To ease transfer of pAR060302, it was moved into a nalixidic acid resistant variant of strain WM3064, which is a DAP auxotroph. To obtain a nalidixic acid resistant WM3064, it was grown at 
$37^{\circ} \mathrm{C}$ with shaking (200 RPM) in LB broth supplemented with DAP overnight. This culture was used to inoculate a new $10 \mathrm{~mL} \mathrm{LB+Dap}$ broth culture, which was incubated for 4 hours at $37^{\circ} \mathrm{C}$ with shaking (200 RPM). The cells were pelleted by centrifugation at 8000 RPM for 10 minutes. The pellet was resuspended with $100 \mu \mathrm{L}$ of LB broth and used to inoculate an LB agar plate supplement with $\mathrm{Nal}$ and Dap to select a spontaneous nalidixic acid resistant mutant (WM3064nalR). This plate was incubated at $37^{\circ} \mathrm{C}$ overnight. Isolated colonies were streak purified on a new $\mathrm{LB}+\mathrm{Nal}+\mathrm{Dap}$ agar plate.

The pAR060302 parental E. coli strain, AR060302, was mated with WM3064nalR. Briefly, WM3064nalR was struck on an LB+Dap plate and the WT strain AR060302 was struck over the top. The plate was incubated overnight. The resulting growth was struck onto an $\mathrm{LB}+\mathrm{Nal}+\mathrm{CM}+\mathrm{Dap}$ plate to select for WM3064nalR(pAR0603020) transconjugants.

WM3064nalR(pAR060302) was used to transfer pAR060302 into strain DY331 in a similar manner except selection for transconjugants was achieved by growth on $\mathrm{LB}+\mathrm{Cm}$ plates (No DAP) to select for DY331(pAR060302). PCR was used to generate the tet knockout amplicon by amplifying the neo- $c c d B$ cassette from $\mathrm{pKD} 45$ using the primers pARdeltaTet-fw and rv (Table 2) (12.5 $\mu$ L Phusion 2x master mix (Life Technologies ${ }^{\mathrm{TM}}$ ), $500 \mathrm{nM}$ of each primer, $1 \mathrm{uL}$ of template (boiled cells), PCR conditions: $95^{\circ} \mathrm{C} 5 \mathrm{~min}, 25$ cycles of $95^{\circ} \mathrm{C} 30 \mathrm{sec}, 55^{\circ} \mathrm{C} 30 \mathrm{sec}, 72^{\circ} \mathrm{C}^{\circ}$ for $2 \mathrm{~min}$; then a final incubation at $72^{\circ} \mathrm{C}$ for $10 \mathrm{~min})$. The resulting amplicon was purified with a Qiagen ${ }^{\mathrm{TM}}$ PCR cleanup kit. The neo-ccdB cassette from pKD45 allows for selection with kanamycin and then removal of 
the cassette (scar-less or otherwise) using counterselection as expression of $c c d B$ (via growth on minimal rhamnose plates) is lethal.

Strain DY331(pAR060302) was grown in $\mathrm{LB}+\mathrm{Cm}$ broth at $32^{\circ} \mathrm{C}$ with shaking $(200$ $\mathrm{RPM}$ ) for overnight. The overnight culture was used to inoculate a new $50 \mathrm{~mL} \mathrm{LB}+\mathrm{Cm}$ broth culture (1:100 dilution). This was grown until an OD600 0.4 at which time it was moved to a $43^{\circ} \mathrm{C}$ shaking water bath and incubated for 20 min to prime cells for recombineering. After the incubation the flask was cooled on ice for $10 \mathrm{~min}$. The cells were pelleted by centrifugation at $8000 \mathrm{RPM}$ for $5 \mathrm{~min}$ at $4^{\circ} \mathrm{C}$. The cell pellet was resuspended with $25 \mathrm{~mL}$ ice cold $\mathrm{H}_{2} \mathrm{O}$. The cells were collected again by centrifugation and washed an additional time. The final cell pellet was resuspended in $200 \mu \mathrm{L}$ of ice cold $\mathrm{H}_{2} \mathrm{O}$. A $40 \mu \mathrm{L}$ aliquot of washed cells was electroporated with $0.5-1 \mu \mathrm{g}$ of purified amplicon. Cells were recovered with LB broth and incubated at $32^{\circ} \mathrm{C}$ for 4 hours. After recovery cells were plated on $\mathrm{LB}+\mathrm{Kan}$ plates. Isolated colonies were checked for growth on $\mathrm{LB}+\mathrm{Tet}$ plates to confirm disruption of the tet $(A)$ gene. Successful mutants were mated on LB plates with E. coli strain K-12 MG1655 carrying pSIM5-Tet at $32^{\circ}$ for overnight. Successful transconjugants were selected on $\mathrm{LB}+\mathrm{Cm}+\mathrm{Tet}$ plates to select for pAR060302(Atet::neo-ccdB) and pSIM5-tet. This strain was used to remove the neo$c c d B$ cassette by recombineering using a ssDNA substrate (24). Cells were primed for recombineering as above and the $70 \mathrm{nt}$ oligonucleotide DeltaTetRepairOligo (Table 2) was electroporated. Cells were recovered and plated on $\mathrm{M} 9+\mathrm{Rhamnose}+\mathrm{Cm}$ plates. This resulted in pAR060302( $\Delta$ tet $)$, where the tet locus was deleted and the neo-ccdB cassette was removed. Isolated colonies were checked for mutations via PCR. The entire 
insertion-removal process was then done a second time to target and remove the $b l a_{\mathrm{CMY}-2}$ gene using the appropriate primers. This resulted in pARK01, a tetracycline and ampicillin susceptible variant of pAR060302.

Deletions of predicted transcriptional regulators on pARK01 were done recombineering in strain K12(pARK01, pSIM5-tet). The plasmid pKD4 (25) carrying the FRT-neo-FRT cassette was used as a template for PCR (12.5 $\mu \mathrm{L}$ Phusion 2x master mix (Life Technologies $^{\mathrm{TM}}$ ), $500 \mathrm{nM}$ of each primer, $1 \mathrm{uL}$ of template (boiled cells), PCR conditions: $95^{\circ} \mathrm{C} 5 \mathrm{~min}, 25$ cycles of $95^{\circ} \mathrm{C} 30 \mathrm{sec}, 55^{\circ} \mathrm{C} 30 \mathrm{sec}, 72^{\circ} \mathrm{C}^{\circ}$ for $2 \mathrm{~min}$; then a final incubation at $72^{\circ} \mathrm{C}$ for $\left.10 \mathrm{~min}\right)$. PCR amplicons were subjected to a DpnI digestion to eliminate template plasmid and then electroporated into cells primed for recombineering. Resulting colonies were checked by PCR for mutations. Successful mutants were then grown and made electrocompetent and the plasmid pCP20 was electroporated. These transformants were grown at $32^{\circ} \mathrm{C}$ for 48 hours to "flip" out the neo cassette, leaving a copy of FRT. The plasmid pCP20 was lost via incubation at $37^{\circ} \mathrm{C}$ for 48 hours. Colonies were screened via PCR and amplicons were verified by sequencing.

Alterations in the AT-Hook motif of Acr2 were achieved by first inserting the neo-ccdB cassette (amplified using delATHOOKAcr2-kanccdB-fw and -rv primers) into $a c r 2$, and then through another round of recombineering using the appropriate ssDNA oligo and counterselection on minimal rhamnose plates to remove the cassette and alter the coding sequence as desired. 


\subsection{Molecular cloning methods.}

For constructs using pLUXtet, containing a promoterless lux operon, cloning was done via double digestion with SpeI and BamHI and ligation with DNA ligase (NEB).

Oligonucleotides used to generate PCR amplicons of promoter regions with flanking ends containing restriction sites are listed in Table 2.

To clone genes from pAR060302 into pBAD22 (26), in vivo cloning via recomineering was used (27). In order to generate a template for PCR, pBAD22 was digested overnight using BamHI. The resulting digestion was used as template for PCR (12.5 $\mu$ L Phusion 2x master mix (Life Technologies ${ }^{\mathrm{TM}}$ ), $500 \mathrm{nM}$ of each primer, $1 \mathrm{uL}$ of template, PCR conditions: $95^{\circ} \mathrm{C} 5 \mathrm{~min}, 25$ cycles of $95^{\circ} \mathrm{C} 30 \mathrm{sec}, 55^{\circ} \mathrm{C} 30 \mathrm{sec}, 72^{\circ} \mathrm{C}^{\circ}$ for $6 \mathrm{~min}$; then a final incubation at $72^{\circ} \mathrm{C}$ for $10 \mathrm{~min}$ ). Primers used for in vivo cloning were designed to amplify the vector $\mathrm{pBAD} 22$, and add 40 bp regions of homology starting with $2^{\text {nd }}$ codon of the gene of interest to the reverse primer and $40 \mathrm{bp}$ of homology ending with the codon next to the stop codon for the forward primer. PCR amplicons were purified with a

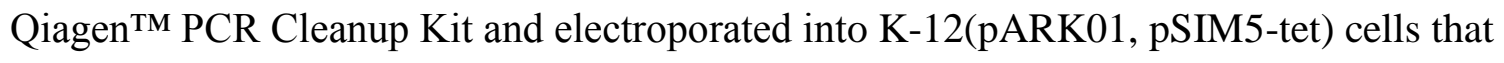
were primed for recombineering. After 4 hours of recovery in LB broth at $32^{\circ} \mathrm{C}$, cells were plated on $\mathrm{LB}+\mathrm{Amp}+\mathrm{Cm}$ plates to select for strains still carrying pARK01 as well as the newly recombined pBAD22 with appropriate insertion. Subsequent colonies were check via PCR for insertions in pBAD22. Successfully cloned plasmids were confirmed via DNA sequencing. The pSIM5-tet plasmid was lost by incubation at $37^{\circ} \mathrm{C}$ for 24 hours. 


\subsection{Conjugation experiments.}

E. coli strain DH10 was used as a recipient in all conjugation assays. Donor and recipient cells were grown overnight at $37^{\circ} \mathrm{C}$ in $\mathrm{LB}$ broth with the appropriate selection. The overnight cultures were used to inoculate new $5 \mathrm{~mL}$ cultures in $\mathrm{LB}$ broth with no selection. The new cultures were incubated for 4 hours; if arabinose induction was needed it was done at 2 hours of incubation. After 4 hours of incubation, $0.5 \mathrm{~mL}$ of donor and recipient cells were added to $1.5 \mathrm{~mL}$ centrifuge tube, mixed by pipetting and incubated at $37^{\circ} \mathrm{C}$ without shaking for 1 hour. The mating reactions were then vortexed and placed immediately on ice. They were subsequently diluted in $1 \mathrm{x}$ phosphate buffered saline (PBS) and plated to select for transconjugants and donors.

\subsection{Lux reporter assays.}

Overnight cultures were grown with the appropriate selections in $\mathrm{LB}$ broth at $37^{\circ} \mathrm{C}$ with shaking (200 RPM). These cultures were diluted 1:100 in new broth with selection. These cultures were grown under the same conditions for 2 hours. At that time, the cultures were split in half. One half was treated with arabinose $(0.02 \%)$ and the other half received no treatment. The cultures were allowed to grow for 2 hours. All cultures were then aliquoted into a 96-well plate, $200 \mu 1$ per well. Plates were then read on a Bio-Tek plate reader. Cell density and arbitrary light units were measured. Bioluminescence was standardized for cell density by dividing light units by the OD600 absorbance. Each value represents the mean of 3 experiments. 


\subsection{RNA isolation and sequencing for RNA-Seq.}

Strains DH10B(pAR) and DH10B(pAR $\triangle a c r 2)$ were grown until an $\mathrm{OD}_{600}$ of 0.5 was achieved. Cells were pelleted and RNA was purified using a commercially available RNA extraction kit (Qiagen). Treatments were included to remove DNA contamination (Qiagen) and ribosomal RNA (MicrobExpress, Ambion). Two biological replicates for each strain were pooled for paired-end library sequencing (either 50 or 100 bp reads) via Illumina Genome Analyzer II at the Biomedical Genomics Center at the University of Minnesota. All of the sequencing data are publically available under the NCBI BioProject ID PRJNA273283.

\subsection{RNA-Seq Analysis.}

All Perl scripts and other computational biology resources used in this study can be found at https://github.com/kevinslang. cDNA reads were first trimmed so that the quality at each base position was above 30 and then mapped to the appropriate genome or plasmid sequence (for pAR060302, Genbank accession no. NC_012692, for DH10, the E. coli K12 MG1655 published sequence was used Genbank accession no. NC_000913) Read mapping was done using BOWTIE (28). For each host, transcriptome maps of pAR060302 were constructed using Circos (29). To achieve this, a table was generated containing the average number of reads mapped per $250 \mathrm{bp}$ of plasmid sequence. Each average was then normalized per 1 million total reads in the cognate sequence library. These averages were then log transformed and plotted as a line plot. For statistical testing of differentially expressed genes, the total number of reads mapped to each coding sequence (CDS) was calculated using Perl. These values were then analyzed using the $\mathrm{R}$ 
package EdgeR $(30,31)$. We conservatively estimated the dispersion at 0.001 . A foldchange cutoff of $>2$ or $<-2$ and an adjusted $p$-value of $<0.05$ were used to define significantly differentially expressed genes.

\subsection{ChAP-Seq experiments.}

$\mathrm{K} 12\left(\mathrm{pARK} 01, \mathrm{pB} a c r 2^{6 \mathrm{xHis}}\right.$ ) was grown overnight in $\mathrm{LB}+\mathrm{Cm}+\mathrm{Amp}$ at $37^{\circ} \mathrm{C}$ with shaking (200 RPM). The overnight culture was used to inoculate a new $10 \mathrm{~mL} \mathrm{LB}+\mathrm{Cm}+\mathrm{Amp}$ culture (1:100 dilution). This was grown for 2 hours at $37^{\circ} \mathrm{C}$ with shaking (200 RPM). Arabinose was added to a final concentration of $0.02 \%$ and the culture was incubated for 2 additional hours. Cells were fixed with the addition of formalin to a final concentration of $1 \%$. Fixed cells were incubated at RT for $20 \mathrm{~min}$. The formalin was quenched by addition of glycine to a final concentration of $0.5 \mathrm{M}$ and incubation for $5 \mathrm{~min}$ at RT. Cells were collected by centrifugation at $8000 \mathrm{RPM}$ for $5 \mathrm{~min}$. The cell pellet was washed 1x with $10 \mathrm{~mL}$ of cold PBS and collected again. The resulting pellet was resuspended in $1 \mathrm{X}$ lysis solution (MagnaHIS Kit ${ }^{\mathrm{TM}}$, Promega). The cells were sonicated on ice at 5 watts for 30 second intervals and 1 min rest times. This was done 10 times. The cell lysates were spun at $12,000 \mathrm{~g}$ for $5 \mathrm{~min}$ and the supernatant was moved to a $1.5 \mathrm{~mL}$ centrifuge tube containing $50 \mu \mathrm{L}$ of MagneHIS particles. This suspension was taken through the MagneHIS kit protocol. After elution, cross-linked DNA was released via incubation at $65^{\circ} \mathrm{C}$ for 18 hours. The resulting DNA was purified with a Qiagen ${ }^{\mathrm{TM}}$ PCR Clean up Kit and sent for paired-end sequencing using the Illumina MiSeq platform. The library generation and sequencing was done at the UMGC at the University of Minnesota. In total, 2 biological replicates were sequenced separately. As a negative control, two 
genomic DNA preparations of the same cells were done using a Qiagen ${ }^{\mathrm{TM}}$ DNeasy ${ }^{\mathrm{TM}}$ kit and $\sim 400 \mathrm{ng}$ of each was sent for sequencing.

The reads that resulted from the MiSeq run were all trimmed to $50 \mathrm{bp}$ from the 3' end using the tool Trimmomatic (32). The trimmed reads were then mapped to either the pAR060302 sequence or the K-12 genome sequence using BWA using the default parameters (33). Reads that were mapped correctly were filtered using SamTools (34). The replicate libraries were then merged using SamTools. The resulting read alignments files were then analyzed using MACS (35). Peak summit coordinates were used to extract $200 \mathrm{bp}$ of sequence surrounding them using BedTools (36). These sequences were combined into a multifasta file and submitted to MEME for motif analysis (37). ChAPSeq read alignments were also subjected to read counting on $150 \mathrm{bp}$ windows of the pAR060302 sequence for visualization in Circos (29).

\subsection{Protein purification and EMSA.}

The $\mathrm{pB} a \mathrm{cr}{ }^{6 \mathrm{xHis}}$ construct was introduced into strain were transformed into the BL21 (DE3) strain. The resulting strains were cultured in $\mathrm{LB}+\mathrm{AMP}$ at $37^{\circ} \mathrm{C}$ for 1 hour with shaking (250 RPM). Arabinose was added to a final concentration of $0.2 \%$ prior to growing the cultures for $5 \mathrm{~h}$ at $28^{\circ} \mathrm{C}$. Cells were spun at $4500 \times \mathrm{g}$ for $30 \mathrm{~min}$, resuspended in $5 \mathrm{~mL}$ cell lysis buffer $(20 \mathrm{mM}$ Tris $\mathrm{pH} 8,500 \mathrm{mM} \mathrm{NaCl}, 5 \mathrm{mM}$ imidazole, $5 \mathrm{mM} \beta$ mercaptoethanol) and sonicated. The cellular debris was removed by centrifugation at 12,000 g for $15 \mathrm{~min} .200 \mu \mathrm{L}$ of MagnePURE beads were added to the supernatant and these were incubated for $1 \mathrm{~h}$ on a rocking platform, washed twice with high salt washing 
buffer (20 mM Tris $\mathrm{pH} 8,1 \mathrm{M} \mathrm{NaCl}, 5 \mathrm{mM} \beta$-mercaptoethanol) and twice with low salt washing buffer (20 mM Tris $\mathrm{pH} 8,0.5 \mathrm{M} \mathrm{NaCl}, 30 \mathrm{mM}$ imidazole, $5 \mathrm{mM} \beta$ mercaptoethanol), and then eluted with $100 \mu \mathrm{L}$ elution buffer (20 mM Tris pH 8, 500 $\mathrm{mM} \mathrm{NaCl}, 500 \mathrm{mM}$ imidazole). Pefabloc ${ }^{\mathrm{TM}}$ (Roche) and glycerol were added to final concentrations of $1 \mathrm{mg} / \mathrm{mL}$ and $5 \%$, respectively. Purified proteins were analyzed by SDS-PAGE gel electrophoresis and stored at $-80^{\circ} \mathrm{C}$.

Two DNA fragments were used for EMSA analysis. The region upstream of acrl ( 480 bp) and the floR promotor ( $150 \mathrm{bp})$. These fragments were amplified by PCR using the primers Orf184-EMSA-F and Orf184-EMSA-R (acrl) and Flo-F and Flo-R (floR). The amplicons were purified using a PCR cleanup kit (Qiagen). Various concentrations of purified Acr2 were incubated with $10 \mathrm{nM}$ DNA in binding buffer (15 mM HEPES pH 7.9, $40 \mathrm{mM} \mathrm{KCl,} 1 \mathrm{mM}$ EDTA, $1 \mathrm{mM}$ DTT, 5\% glycerol) for 30 minutes. The reactions were separated by gel electrophoresis for $2.5 \mathrm{~h}$ at $70 \mathrm{~V}$ on a $7.5 \%$ native polyacrylamide gel at $4{ }^{\circ} \mathrm{C}$ (buffered with Tris glycine $\mathrm{pH}$ 8.0). Gels were stained with SYBR Green for 20 minutes at room temperature, washed twice with ddH2O, and DNA complexes were visualized with ultraviolet light.

\subsection{Development of acr1-lacZ fusion construct and detection of LacZ activity.}

Recombineering was used to replace the E. coli chromosomal genes lacY and lacA with an FRT-neo-FRT cassette (Figure 21a). The lacZ gene, starting at the $4^{\text {th }}$ codon was then amplified, along with the FRT-neo-FRT cassette with primers that contained $40 \mathrm{bp}$ of homology with $a c r l$ and the region upstream of $\operatorname{acr} C$. This amplicon was used to replace 
acrl-acrC starting with the $4^{\text {th }}$ codon of acrl in strain MC4100(pARK01, pSIM5-Tet) via recombineering and the neo-FRT cassette was removed by introduction of $\mathrm{pCP} 20$ expressing the FLP recombinase. In the same strain, acr2 was disrupted via recombineering. These reporter cells were then transformed with constructs over expressing Acr2 and the relevant Acr2 variants. They were struck onto LB+Amp+Xgal plates with and without arabinose.

\section{RESULTS}

\subsection{Acr2 is an $\mathrm{H}$-NS-like protein that represses conjugative transfer of IncA/C} plasmids.

To further investigate IncA/C plasmid conjugation, we developed a plasmid variant by systematically deleting the tetracycline and beta-lactam resistance genes (see Materials and Methods) to generate pARK01. We demonstrate that this variant is no different in terms of conjugation frequency than the wild-type plasmid (Figure S1A). Recently, several transcriptional regulators on the IncA/C plasmid $\mathrm{pVCR} 94 \Delta \mathrm{X}$ were characterized in terms of their ability to regulate conjugative transfer (7). However, pVCR94 $\triangle \mathrm{X}$ was isolated from a Vibrio isolate and a deletion of unknown content was made in its development for genetic studies (6). To be certain that the functions were conserved in our IncA/C plasmid, pAR060302 (isolated from an E. coli), we repeated several experiments using mutants of pAR060302. Our results were mostly consistent with what was previously found (Figure S1C and S1D), which indicated that pAR060302 was regulated in a similar matter to $\mathrm{pVCR} 94 \Delta \mathrm{X}$. The putative protein encoded by $\operatorname{orf} 183$ shares homology only with hypothetical proteins. Because of its proximity to the other 
predicted transcriptional regulators, we wondered if it may be involved in regulating conjugative transfer (Figure S1B). Deletion of this gene does result in a slight increase in transconjugants, however we could not rule out that this was due to a polar effect of the deletion (Figure S1C). Given the small magnitude of the effect, the putative protein produced by orf183 is unlikely to be a major contributor to repression of conjugation. In our experiments, deletion of acrl did not alter the frequency of conjugative transfer of pARK01. However, given the strong evidence previously reported on acrl (7), we acknowledge that this could be due to differences in our experimental set up.

To further investigate Acr2, we generated an $\mathrm{Acr} 2^{6 \mathrm{xHis}}$ construct and confirmed its ability to complement an acr2 deletion mutant by conducting transfer experiments. Plasmids lacking acr2 exhibit a 10-fold increase in conjugation frequency compared to wild-type (Figure 1). The observation, from our data and that of other's (7), that Acr2 negatively regulates conjugation corroborated our RNA-Seq results comparing WT and $\Delta a c r 2$ plasmids. Nearly all of the genes that are predicted to be involved in conjugative transfer were significantly up-regulated (at least 2 -fold and p-value $<0.05$ ) in the $\Delta a c r 2$ strain (Figure $2,4^{\text {th }}$ ring). In addition to genes involved with transfer being up-regulated, the region encoding many putative hypothetical proteins and putative phage-like proteins (bp positions $\sim 82 \mathrm{k}-100 \mathrm{k}$ ) were also up-regulated in our experiment. Again these results are congruent with what has previously been reported, demonstrating that pARK01 is regulated in the same manner as other IncA/C plasmids and that our $\mathrm{Acr} 2^{6 \mathrm{xHis}}$ construct is functionally analogous to the wild-type protein. 


\subsection{Characterization of Acr2 binding sites.}

We performed a ChAP-Seq experiment in vivo to better understand where Acr2 binds on both the plasmid and host bacterial chromosome. Using nickel affinity chromatography to pull down Acr2 ${ }^{6 \mathrm{xHis}}$, cross-linked DNA was extracted and subsequently sequenced. Analysis of the ChAP-Seq data revealed that Acr $2^{6 x H i s}$ binds to several loci on the plasmid (Figure 2, rings 1 and 2). Some of the ChAP peaks overlapped with genes of unknown function, such as near base pair coordinates 19k, 45k, 140k, and 145k. The regions that showed greatest binding were the entire ISEcpl region, the regions within the $\operatorname{traFHG}$ and the region upstream of $a c r l$. Binding upstream of $a c r l$ would suggest a direct repression of the operon encoding the positive regulators acrDC.

Our ChAP data suggests that Acr $2^{6 x H i s}$ binds to chromosomal DNA sequences. However, like other H-NS-like proteins, the interactions are not easily interpretable. For example, we only found 3 instances of binding of genes that were subsequently found to be significantly differentially expressed in our RNA-Seq data (Figure 3). Interestingly, all three of these genes have functions associated with metabolism, most notably the $g l c B$ gene which was found previously as being up regulated in E. coli carrying pAR060302, compared to cells lacking the plasmid (38).

We used MACS (Model-based Analysis of ChAP-Seq) (35) to determine significantly enriched peaks in DNA pulled down with Acr $2^{6 x H i s}$. The sequence surrounding the summits of each of the significant ChAP peaks found by MACS was submitted to MEME (Multiple Em for Motif Elicitation) to determine if there were common motifs within the 
significant peaks. The motif discovered in a majority of the peaks is $\mathrm{A}+\mathrm{T}$ rich, similar to that of other H-NS-like proteins (Figure 4B). Electromobility shift assays (EMSA) were used to confirm that Acr ${ }^{6 \times H i s}$ binds to the DNA fragment upstream of $a c r 1$ containing the motif, but not a different $\mathrm{A}+\mathrm{T}$ rich promoter sequence located upstream of the floR gene on plasmid pAR060302 (Figure 4A). Analysis using the tool Bprom (39) to computationally predict bacterial promoters shows a predicted transcriptional start site 287 bp upstream of the start codon of acrl (Figure 4C). These results demonstrate that Acr2 directly represses transcription of the operon containing $a c r D C$ by binding to the sequence upstream of $a c r l$ and that there is sequence specificity to Acr2 binding regardless of $\mathrm{A}+\mathrm{T}$ content.

\subsection{The C-terminal domain of Acr2 is crucial for its activity.}

The C-terminal domain of Acr2 is similar to that of other H-NS-like proteins (Figure 5A). It contains an AT-hook motif, with conserved amino acids Q/RGR, that has been shown in structure studies to be critical to contact with DNA (40). We examined the possibility that this motif was important for Acr2 activity by making mutations in this region using recombination with a ssDNA substrate (see Materials and Methods). An in-frame deletion of the codons for QGRRPD ( $\triangle$ AT-hook) resulted in abolishment of the ability of Acr2 to repress conjugative transfer (Figure 5B). Although substitution of alanine for glutamine at position 116 resulted in increased transfer frequency, it was not as a dramatic as the increase observed for alanine substitutions for the arginine residues at positions 118 and 119 (Figure 5B). Given that these substitutions could have led to proteins targeted for degradation, which could also explain the $a c r 2^{-}$phenotypes 
observed, we cloned each of these Acr2 variants in an arabinose inducible vector. We used these constructs to test the ability to repress the LacZ activity of an acrl-lacZ fusion construct (Figure 5C). Only the WT Acr2 and the Q116A variant were able to repress LacZ activity. The Q116A result contrasts with that of the conjugation experiment. In the conjugation experiment the Acr2 variants were under native promotion. This is probably much lower than that achieved by arabinose induction of the pBAD vector, however, we cannot rule out the possibility of degradation. Taken together, these results suggest that the QGRR motif is critical for the ability of Acr2 to repress the promoter upstream of acrl.

\section{DISCUSSION}

\subsection{The expanded Acr2 regulon.}

Figure 6 displays our proposed model for the regulation of transfer built from the results of our work, as well as others $(6,7)$. We showed that this is, at least in part, due to a direct interaction between Acr2 and the sequence upstream of acr 1. Our ChAP-Seq data suggest that Acr2 binds upstream of other genes that are predicted to be important for transfer, namely traF and traG. There are a few hypothetical proteins that are annotated on IncA/C plasmids that are located near or within the transfer-associated loci. For example, orf97 and $\operatorname{orf} 98$ are located just downstream of $\operatorname{traN}$, both of which have no known function nor are similar to any protein sequence with known functions in GenBank. We found a ChAP-Seq peak on the 3' end of traN near orf97. It is difficult to understand the function of such an interaction due to the ambiguity of hypothetical proteins such as orf97. 
There are other mechanisms that contribute to the repression of conjugation. In this work we found that orf183 represses conjugation by a mechanism that is unclear. The predicted protein sequence encoded by orf183 shares no similarity to proteins with known functions in protein databases. Certainly, more work needs to be done to understand the product of orf183 to understand if its role is truly to act as a repressor of conjugation. In our experiments, an acrl deletion did not exhibit an effect on conjugative transfer. This contrasts elegant experiments recently published showing that Acr1 represses conjugation and binds the sequence upstream of $\operatorname{acrl}$ (7), and we wonder if subtle differences in our experimental design are responsible for the discrepancy in phenotype. We predict that there might be another factor involved in repressing conjugation of IncA/C plasmids. The setR gene of the integrative conjugative element SXT of Vibrio species is a strong repressor of conjugation, so much so that its deletion is lethal (41). None of the known repressors of IncA/C transfer, described in this work or elsewhere, exhibit this phenotype. Intuitively, if the cost of conjugation is so high, one would conclude that it must be turned on only when needed.

\subsection{Acr2 is an H-NS-like protein with a conserved DNA binding motif.}

Our results demonstrate that, like other H-NS homologs, Acr2 binds A+T rich DNA. Our in vitro results suggest that Acr2 binds in a sequence specific manner. It has been proposed that the amino acid composition in the AT-hook motif is the mechanism by which different H-NS homologs distinguish between chromosomal and horizontally acquired DNA (40). It is thought that the number or arrangement of positively charged 
amino acids, such as arginine, determine the DNA recognition by H-NS-like proteins. Acr2 shares a DNA binding motif with that of other H-NS homologs and our results show that this set of amino acids is critical for its function as a repressor. When we removed or altered this DNA binding motif from Acr2, we found that, in some cases, the conjugation frequency increased higher than that of an $\Delta a c r 2$ mutation. This result could be explained in two ways: 1) Acr2 variants could be imparting a dominant negative effect on other negative regulators, such as Acr1. Or 2) Acr2 variants could bind the promoter upstream of acrl in such a way as to promote transcription. The AT-hook motif in Acr2 contains an additional arginine residue (R119) that is not shared with other H-NS homologs. We have shown that this arginine is important for the function of Acr2. This difference might result in Acr2 having a distinct propensity to bind specific regions of IncA/C plasmids to accomplish specific tasks, such as repressing conjugation.

\subsection{Other roles for Acr2.}

We have generated evidence that Acr2 might have other roles in the biology of IncA/C plasmids. Our ChAP-Seq data suggest that Acr2 binds nearly the entire ISEcp1 element that carries the $b l a_{\mathrm{CMY}-2}$ gene. Comparative genomics studies have demonstrated that the acquisition of this transposon is a recent event in the evolution of IncA/C plasmids (2-4). Could Acr2 bind newly acquired mobile elements within IncA/C plasmid backbones? Given the propensity for chromosomally encoded H-NS to bind genomic islands, it seems plausible (12). Furthermore, Acr2 binds to the 3' end of the rhs gene located downstream of the class 1 integron (bp coordinate $\sim 146,000$ ). The $r h s$ genes have repeat sequence elements that implicates them in genome shuffling (42). Recent work from Harmer et al. 
suggests that the rhs homolog carried on IncA/C plasmids plays an important role in the diversity of newly integrated mobile elements (4). Binding by Acr2 may inhibit the ability for recombination to happen at the rhs locus. H-NS has recently been shown to play an important role in the evolution of Salmonella, providing stability for its genomic islands (15). Given broad spatial distribution of highly similar variants of IncA/C plasmids, Acr2 binding of $r h s$ could be a mechanism driving IncA/C plasmid evolution.

Our ChAP-Seq experiment also yielded evidence that Acr2 binds chromosomal DNA. It is unclear what the true role of this binding is as nearly all genes bound showed no differential expression in RNA-Seq experiments. We cannot rule out that these peaks might be an artifact of overexpressing Acr2. The lack of differentially expressed genes could also be explained by the presence of chromosomally encoded nucleoid associated proteins, such as H-NS, IHF and others. It will take more sophisticated experiments to tease out the meaning behind these results. There were three bound genes, however, that were differentially expressed in our RNA-Seq data. All three have to do with different metabolic pathways. Interestingly, one of the genes was $g l c B$, which is involved in the glyoxylate bypass pathway. We previously found this pathway to be modulated in several different host bacteria upon acquisition of IncA/C plasmids (38). This lends some credence to the possibility that IncA/C plasmids encode the ability to specifically alter host metabolic pathways to improve fitness of plasmid carrying cells. This presents an almost phage-like scenario where the plasmid co-ops the host bacterium to become adept at carrying and disseminating the plasmid. It is an interesting area of study that future work must explore. 


\section{ACKNOWLEDGMENTS}

The authors would like to thank Dr. Jeff Gralnick (University of Minnesota), Dr. Fitnat Yildiz (UC Santa Cruz), and Dr. Don Court (NIH) for sharing of strains. The authors thank Dr. William Navarre (University of Toronto) for sharing purified H-NS and EMSA technical assistance. Data analysis was carried out using tools available through the Minnesota Supercomputing Institute at the University of Minnesota. The primary author, KSL, was supported by a fellowship from the United States Department of Agriculture National Institute of Food and Agriculture grant no. 2013-67011-21276. TJJ was supported through funding from the University of Minnesota College of Veterinary Medicine Signature Programs.

\section{BIBLIOGRAPHY}

1. Welch TJ, Fricke WF, McDermott PF, White DG, Rosso M-L, Rasko DA, Mammel MK, Eppinger M, Rosovitz MJ, Wagner D, Rahalison L, Leclerc JE, Hinshaw JM, Lindler LE, Cebula TA, Carniel E, Ravel J. 2007. Multiple antimicrobial resistance in plague: an emerging public health risk. PLoS One 2:e309.

2. Fernández-Alarcón C, Singer RS, Johnson TJ. 2011. Comparative genomics of multidrug resistance-encoding IncA/C plasmids from commensal and pathogenic Escherichia coli from multiple animal sources. PLoS One 6:e23415.

3. Fricke WF, Welch TJ, McDermott PF, Mammel MK, LeClerc JE, White DG, 
Cebula TA, Ravel J. 2009. Comparative genomics of the IncA/C multidrug resistance plasmid family. J. Bacteriol. 191:4750-4757.

4. Harmer CJ, Hall RM. 2014. pRMH760, a Precursor of A/C2 plasmids carrying bla $_{\mathrm{CMY}}$ and bla $_{\mathrm{NDM}}$ genes. Microb. Drug Resist. 00:1-9.

5. Fricke WF, Mammel MK, McDermott PF, Tartera C, White DG, LeClerc JE, Ravel J, Cebula TA. 2011. Comparative genomics of 28 Salmonella enterica isolates: Evidence for CRISPR-mediated adaptive sublineage evolution. J. Bacteriol. 193:3556-3568.

6. Carraro N, Sauvé M, Matteau D, Lauzon G, Rodrigue S, Burrus V. 2014. Development of pVCR94 $\Delta \mathrm{X}$ from Vibrio cholerae, a prototype for studying multidrug resistant IncA/C conjugative plasmids. Front. Microbiol. 5:44.

7. Carraro N, Matteau D, Luo P, Rodrigue S, Burrus V. 2014. The master activator of IncA/C conjugative plasmids stimulates genomic islands and multidrug resistance dissemination. PLoS Genet. 10:e1004714.

8. Dillon SC, Dorman CJ. 2010. Bacterial nucleoid-associated proteins, nucleoid structure and gene expression. Nat. Rev. Microbiol. 8:185-195.

9. Fang F, Rimsky S. 2008. New insights into transcriptional regulation by H-NS. Curr. Opin. Microbiol. 11:113-120.

10. Bouffartigues E, Buckle M, Badaut C, Travers A, Rimsky S. 2007. H-NS cooperative binding to high-affinity sites in a regulatory element results in transcriptional silencing. Nat. Struct. Mol. Biol. 14:441-8.

11. Ali SS, Whitney JC, Stevenson J, Robinson H, Howell PL, Navarre WW. 
2013. Structural insights into the regulation of foreign genes in Salmonella by the Hha/H-NS complex. J. Biol. Chem. 288:13356-69.

12. Navarre WW, Porwollik S, Wang Y, McClelland M, Rosen H, Libby SJ, Fang FC. 2006. Selective silencing of foreign DNA with low GC content by the H-NS protein in Salmonella. Science (80-. ). 313:236-238.

13. Stoebel DM, Free A, Dorman CJ. 2008. Anti-silencing: overcoming H-NSmediated repression of transcription in Gram-negative enteric bacteria. Microbiology 154:2533-2545.

14. Dorman CJ. 2007. H-NS, the genome sentinel. Nat. Rev. Microbiol. 5:157-161.

15. Ali SS, Soo J, Rao C, Leung AS, Ngai DH-M, Ensminger AW, Navarre WW. 2014. Silencing by H-NS potentiated the evolution of Salmonella. PLoS Pathog. 10:e1004500.

16. Navarre WW, McClelland M, Libby SJ, Fang FC. 2007. Silencing of xenogeneic DNA by H-NS - Facilitation of lateral gene transfer in bacteria by a defense system that recognizes foreign DNA. Genes Dev. 21:1456-1471.

17. Yun C-SS, Suzuki C, Naito K, Takeda T, Takahashi Y, Sai F, Terabayashi T, Miyakoshi M, Shintani M, Nishida H, Yamane H, Nojiri H. 2010. Pmr, a histone-like protein H1 (H-NS) family protein encoded by the IncP-7 plasmid pCAR1, is a key global regulator that alters host function. J. Bacteriol. 192:47204731.

18. Dillon SC, Cameron ADS, Hokamp K, Lucchini S, Hinton JCD, Dorman CJ. 2010. Genome-wide analysis of the H-NS and Sfh regulatory networks in 
Salmonella Typhimurium identifies a plasmid-encoded transcription silencing mechanism. Mol. Microbiol. 76:1250-65.

19. Müller CM, Schneider G, Dobrindt U, Emödy L, Hacker J, Uhlin BE. 2010. Differential effects and interactions of endogenous and horizontally acquired $\mathrm{H}$ NS-like proteins in pathogenic Escherichia coli. Mol. Microbiol. 75:280-293.

20. Bustamante VH, Santana FJ, Calva E, Puente JL. 2001. Transcriptional regulation of type III secretion genes in enteropathogenic Escherichia coli: Ler antagonizes H-NS-dependent repression. Mol. Microbiol. 39:664-678.

21. Forns N, Baños RC, Balsalobre C, Juárez A, Madrid C. 2005. Temperaturedependent conjugative transfer of R27: role of chromosome- and plasmid-encoded Hha and H-NS proteins. J. Bacteriol. 187:3950-9.

22. Doyle M, Fookes M, Ivens A, Mangan MW, Wain J, Dorman CJ. 2007. An HNS-like stealth protein aids horizontal DNA transmission in bacteria. Science (80-. ). 315:251-252.

23. Shintani M, Suzuki-Minakuchi C, Nojiri H. 2015. Nucleoid-associated proteins encoded on plasmids: Occurrence and mode of function. Plasmid 80:32-44.

24. Sawitzke JA, Costantino N, Li X, Thomason LC, Bubunenko M, Court C, Court DL. 2011. Probing cellular processes with oligo-mediated recombination and using the knowledge gained to optimize recombineering. J. Mol. Biol. 407:4559.

25. Datsenko KA, Wanner BL. 2000. One-step inactivation of chromosomal genes in Escherichia coli K-12 using PCR products. Proc. Natl. Acad. Sci. U. S. A. 
97:6640-6645.

26. Guzman LM, Belin D, Carson MJ, Beckwith J. 1995. Tight regulation, modulation, and high-level expression by vectors containing the arabinose PBAD promoter. J. Bacteriol. 177:4121-4130.

27. Lee EC, Yu D, Martinez de Velasco J, Tessarollo L, Swing DA, Court DL, Jenkins NA, Copeland NG. 2001. A highly efficient Escherichia coli-based chromosome engineering system adapted for recombinogenic targeting and subcloning of BAC DNA. Genomics 73:56-65.

28. Langmead B, Trapnell C, Pop M, Salzberg SL. 2009. Ultrafast and memoryefficient alignment of short DNA sequences to the human genome. Genome Biol. 10:R25-R25.

29. Krzywinski M, Schein J, Birol I, Connors J, Gascoyne R, Horsman D, Jones SJ, Marra MA. 2009. Circos: an information aesthetic for comparative genomics. Genome Res. 19:1639-45.

30. Robinson MD, McCarthy DJ, Smyth GK. 2010. edgeR: a Bioconductor package for differential expression analysis of digital gene expression data. Bioinformatics 26: $139-40$.

31. Robinson M, Mccarthy D, Chen Y, Smyth GK. 2011. edgeR : differential expression analysis of digital gene expression data User' s Guide.

32. Bolger AM, Lohse M, Usadel B. 2014. Trimmomatic: a flexible trimmer for Illumina sequence data. Bioinformatics btu170-.

33. Li H, Durbin R. 2009. Fast and accurate short read alignment with Burrows- 
Wheeler transform. Bioinformatics 25:1754-60.

34. Li H, Handsaker B, Wysoker A, Fennell T, Ruan J, Homer N, Marth G, Abecasis G, Durbin R. 2009. The Sequence Alignment/Map format and SAMtools. Bioinformatics 25:2078-9.

35. Zhang Y, Liu T, Meyer CA, Eeckhoute J, Johnson DS, Bernstein BE, Nusbaum C, Myers RM, Brown M, Li W, Liu XS. 2008. Model-based analysis of ChIP-Seq (MACS). Genome Biol. 9:R137.

36. Quinlan AR, Hall IM. 2010. BEDTools: a flexible suite of utilities for comparing genomic features. Bioinformatics 26:841-2.

37. Bailey TL, Boden M, Buske FA, Frith M, Grant CE, Clementi L, Ren J, Li WW, Noble WS. 2009. MEME SUITE: tools for motif discovery and searching. Nucleic Acids Res. 37:W202-8.

38. Lang KS, Johnson TJ. 2015. Transcriptome modulations due to A/C2 plasmid acquisition. Plasmid. 80:83-9.

39. Solovyev V, Salamov A. 2011. Automatic Annotation of Microbial Genomes and Metagenomic Sequences., p. 61-78. In Metagenomics and its Applications in Agriculture, Biomedicine and Environmental Studies. Nova Science Publishers.

40. Gordon BRG, Li Y, Cote A, Weirauch MT, Ding P, Hughes TR, Navarre WW, Xia B, Liu J. 2011. Structural basis for recognition of AT-rich DNA by unrelated xenogeneic silencing proteins. Proc. Natl. Acad. Sci. U. S. A. 108:10690-10695.

41. Beaber JW, Hochhut B, Waldor MK. 2004. SOS response promotes horizontal 
dissemination of antibiotic resistance genes. Nature 427:72-74.

42. Lin RJ, Capage M, Hill CW. 1984. A repetitive DNA sequence, rhs, responsible for duplications within the Escherichia coli K-12 chromosome. J. Mol. Biol. 177:1-18.

43. Mendoza-Vargas A, Olvera L, Olvera M, Grande R, Vega-Alvarado L, Taboada B, Jimenez-Jacinto V, Salgado H, Juárez K, Contreras-Moreira B, Huerta AM, Collado-Vides J, Morett E. 2009. Genome-Wide Identification of Transcription Start Sites, Promoters and Transcription Factor Binding Sites in E. coli. PLoS One 4:e7526.

\section{Figure Legends.}

Figure 1. Conjugation frequency of acr2 mutants. (+) and (-) represent presence or absence of arabinose in the media. Results represent the mean and standard deviation of 3 experiments. Means were compared using a 2-tailed Student's T-test. * indicates p-value $>0.05 ; * * *$ indicates p-value $<0.05$.

Figure 2. Acr2 binding sites on pAR060302. Outer ring (Ring 1) Base pair coordinates of pAR060302. (Ring2) Results of ChAP-Seq experiment. Scale (toward the outer circle) is 
from 0 reads to 1500 on a linear scale. (Ring 3) Enriched peaks (purple bars) as found by MACS (35). (Ring 4) Differentially expressed genes in pAR060302 $\triangle a c r 2$ compared to pAR060302. Color indicates fold-change and FDR $<0.05$. Grey indicates unchanged. (Ring 5) pAR060302 gene map. Genes on the map are positioned by what strand they are coded on and colored by function: gray, hypothetical protein; red, antibiotic resistance; yellow, mobile genetic elements; green, transcriptional regulation; light purple, recombination; purple, DNA binding; blue, conjugal transfer; light blue, transglycosylase; orange, replication. (Ring 6) $\mathrm{G}+\mathrm{C}$ content along $150 \mathrm{bp}$ windows of pAR060302.

Figure 3. Expression of E. coli chromosomal genes carrying either pAR060302 or pAR060302 $\triangle a c r 2$. Normalized expression values were calculated using Perl and are displayed as Reads Per Kilobase of gene length per Millions of total reads (RPKM) on a $\log 10$ scale. Acr2 enriched peaks were found with MACS and annotated with BedTools.

Figure 4. Acr2 binds promoter region of acr1. a) Electromobility Shift Assay using either a fragment of DNA upstream of $a c r l$ (left) or floR (right) combined with either no protein, or increasing protein concentrations of $150 \mathrm{nM}, 200 \mathrm{nM}, 300 \mathrm{nM}, 400 \mathrm{nM}, 500$ $\mathrm{nM}, 600 \mathrm{nM}, 700 \mathrm{nM}$, or $850 \mathrm{nM}$. DNA-protein complexes were separated on a $7.5 \%$ native acrylamide gel. The black triangle indicates a bound DNA complex. b) Consensus DNA binding sequence of Acr2 as found by MEME (37). $200 \mathrm{bp}$ of sequence surrounding each peak summit found by MACS and compared by MEME. c) Promoter region of acrl 323 bp upstream of acrl start codon. -35, -10 and TSS sites indicated were 
predicted by bprom (43). The underlined sequence is the predicted binding site of Acr2.

Figure 5. Activity of Acr2 variants. A) Alignment of the C-terminal domain of Acr2 and other H-NS-like proteins. Box indicates region of conserved amino acid positions. Red letters indicate the AT hook motif in Acr2. B) pARK01 encoding variants of Acr2 were used in conjugation experiments. Results represent the mean and standard deviation of 3 experiments. C) Alleles encoding Acr2 variants were cloned into pBAD and assayed for their ability to repress the acrl-lacZ fusion construct. Blue color indicates LacZ activity. White color indicates absence of LacZ activity.

Figure 6. Proposed model for the regulation of IncA/C conjugation and Acr2 regulon. Red indicates homology to $f h D C$. Green indicates predicted DNA binding domains. Blue indicates predicted transglycosylase activity. Acr2 and Acr1 have been shown to repress $\mathrm{P}_{\mathrm{acrl}}$ and ORF183 represses conjugation by some unknown mechanism. Expression of $a c a D C$ results in the up-regulation of transfer genes as well as mobilization of other genomic islands. This also may express $a c r 2$, which, in turn, shuts down conjugation. Acr2 acts on other loci on the plasmid including on genes of unknown function and newly acquired DNA.

Figure S1. Summary of experiments regarding the regulators of conjugation. A) Conjugation experiment showing conjugation frequency of donor strains WT strain AR060302 (WT AR), K-12 strain MG1655 carrying pAR060302 (K12 pAR) and K-12 strains MG1655 carrying pARK01 (K12 pARK01). The results represent the means and 
standard deviations of 3 experiments. B) Gene map of the cluster of transcriptional regulators that regulate conjugation. Red indicates homology to $f l h D C$. Green indicates predicted DNA binding domains. Blue indicates predicted transglycosylase activity. C) Conjugation frequency of mutants. (+) and (-) indicate the presence or absence of arabinose in the media. Results represent mean and standard deviation of 3 experiments. Means were compared using a 2-tailed Student's T-test. * indicates p-value >0.05. ** pvalue $<0.05$. *** indicates not detected. D) Activity of promoter fusions to lux operon. Results represent mean and standard deviation of 3 experiments. 


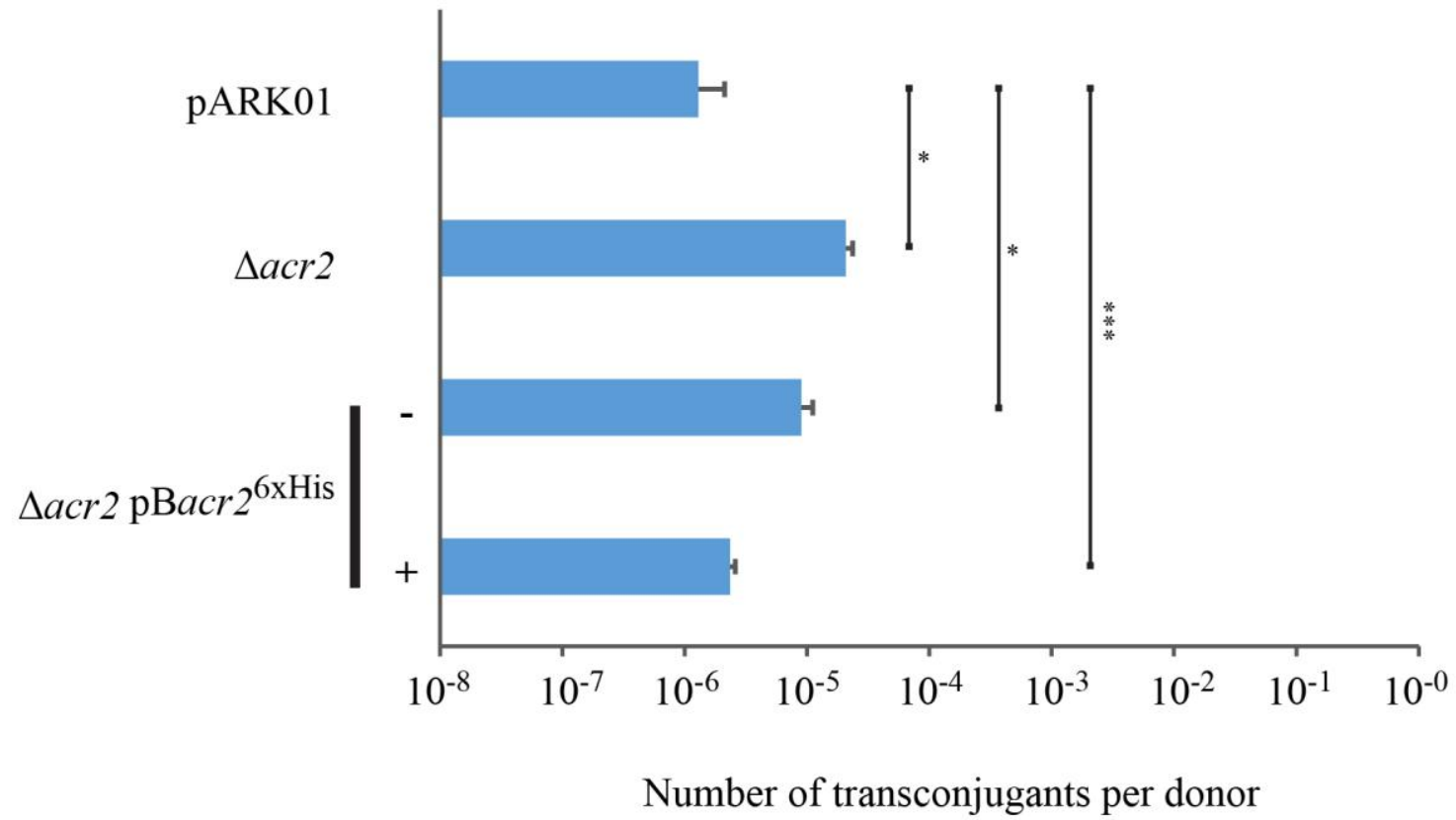




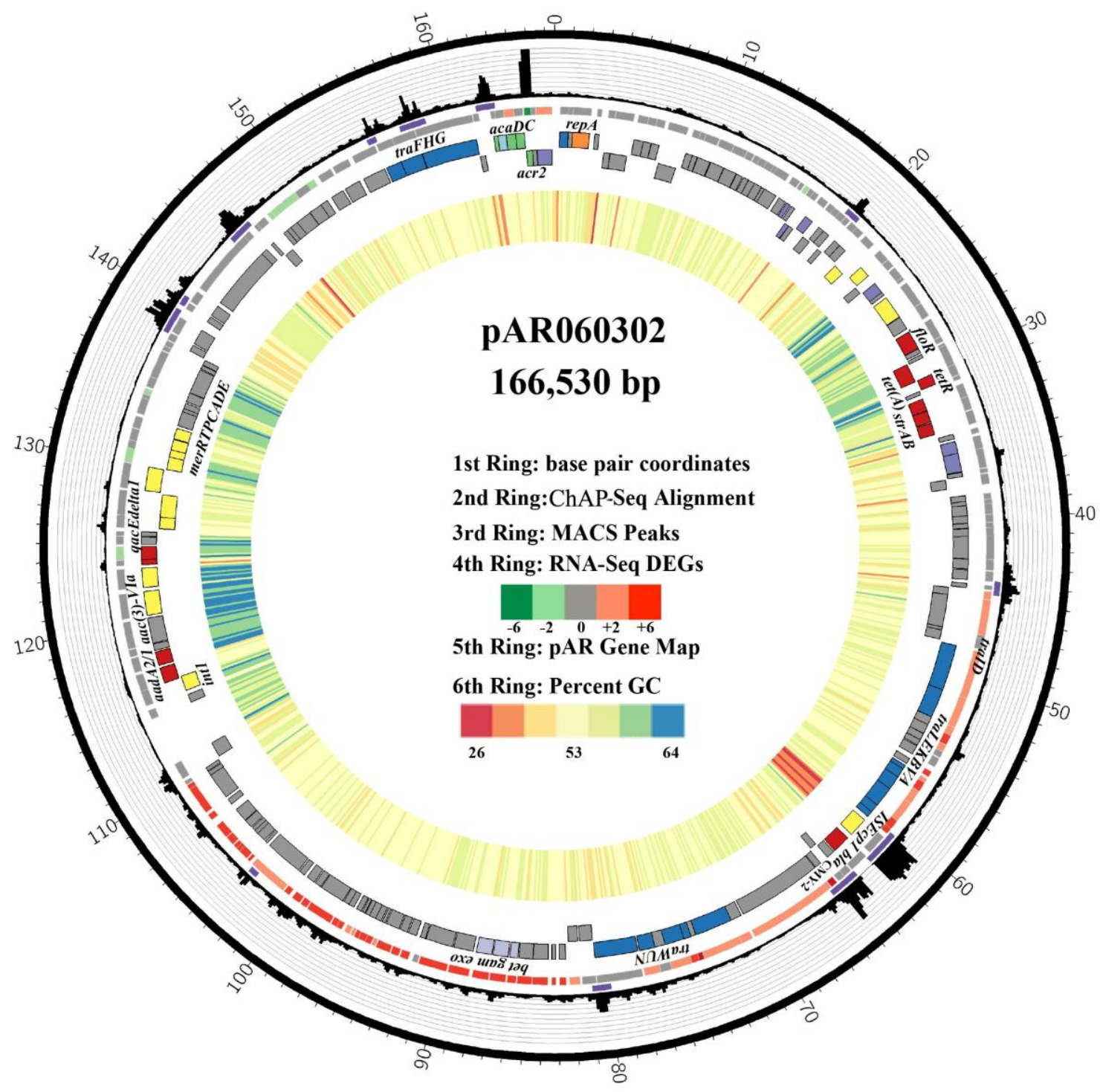




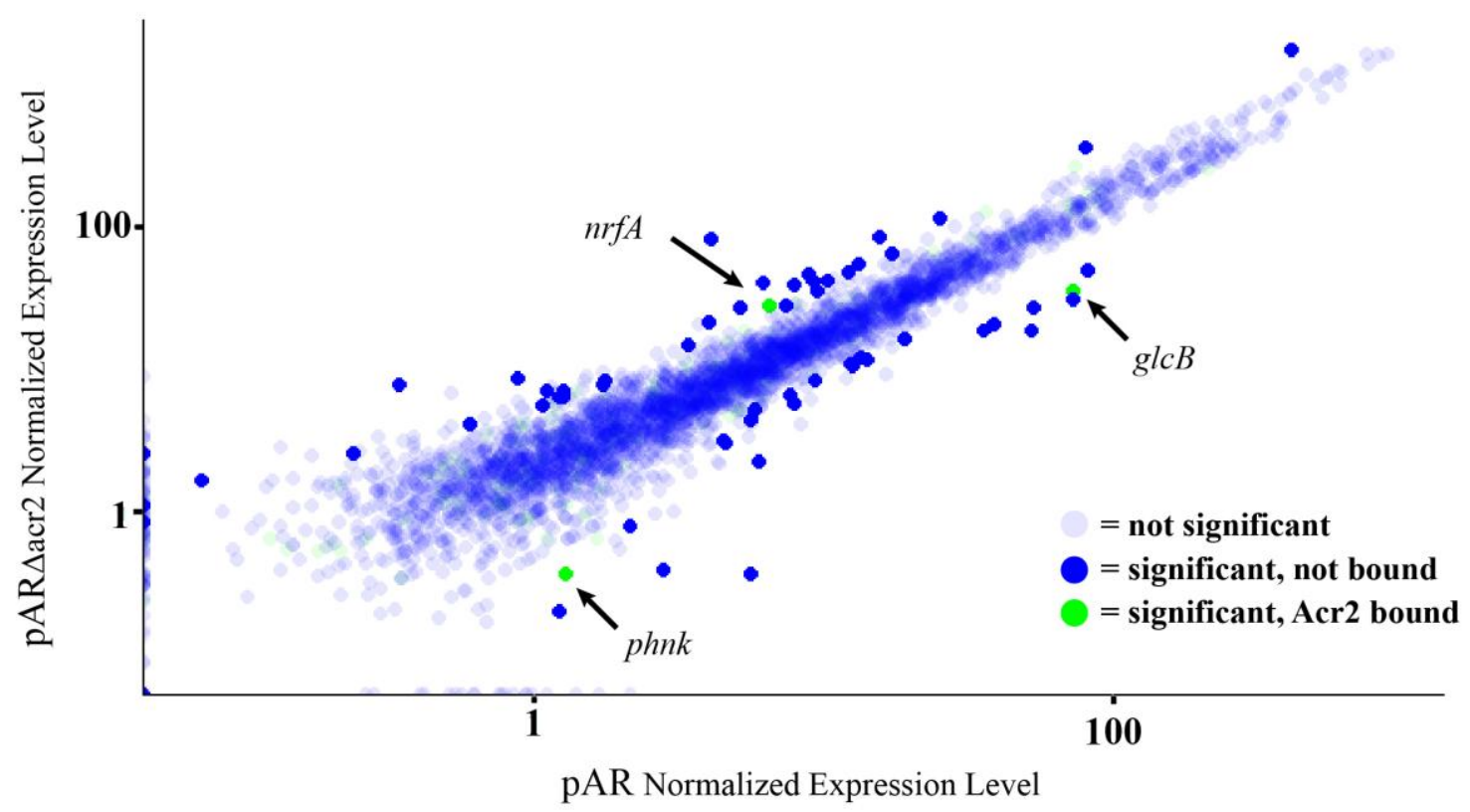


a)
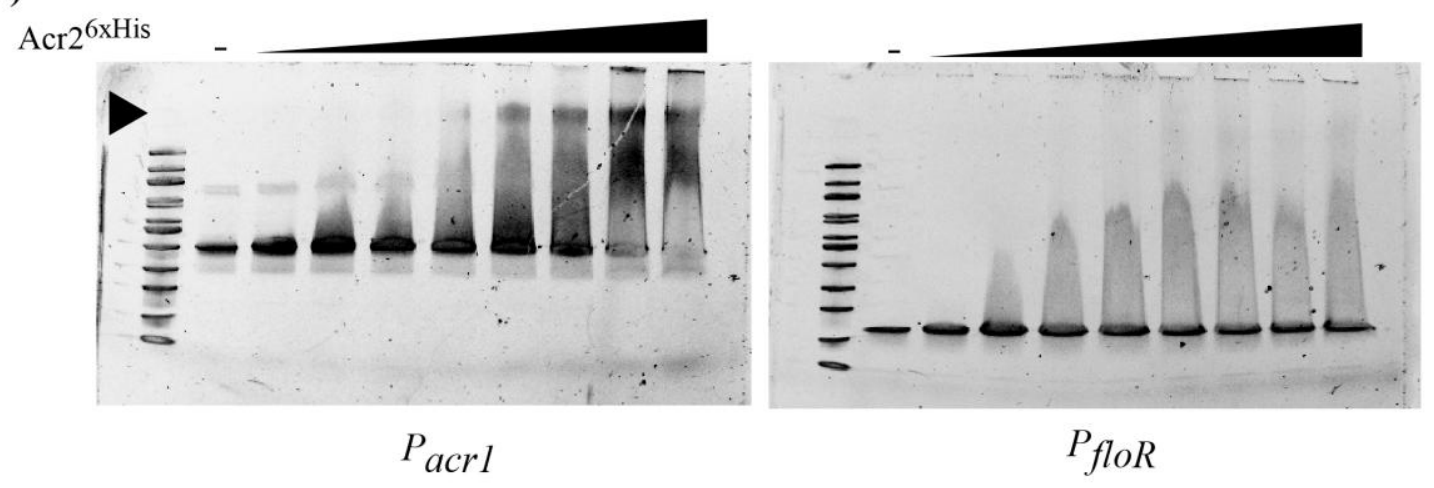

b)

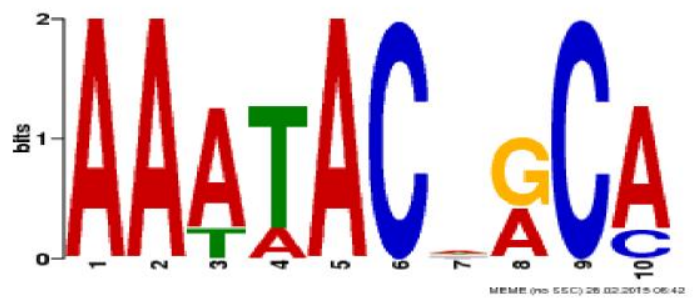

c)

taaatcact tatacctaaacgctatttaatat cacaaaatlaccgcactccccgtgcget $-35$ 
a) 90 -LNEMFTSRSEPDNAKYSKDGVSWSGQGRRPDAFKGL---GAVELERYRIPOKK--- > Acr2 104 -AQRPAKYSYVDENG----ETKTWTGQGRTPAVIKKAMDEQGKSLDDFLIKQ----- > H-NS

71 -MSTVPKYR---DPA----TGKTWSGRGRQPANL-------GNDPAAFLIQPDLPAI > bv3

81 AAIREWARR---------NGHNVSTRGRIPADV----------IDAYHAAT----- > Lsr2

b)

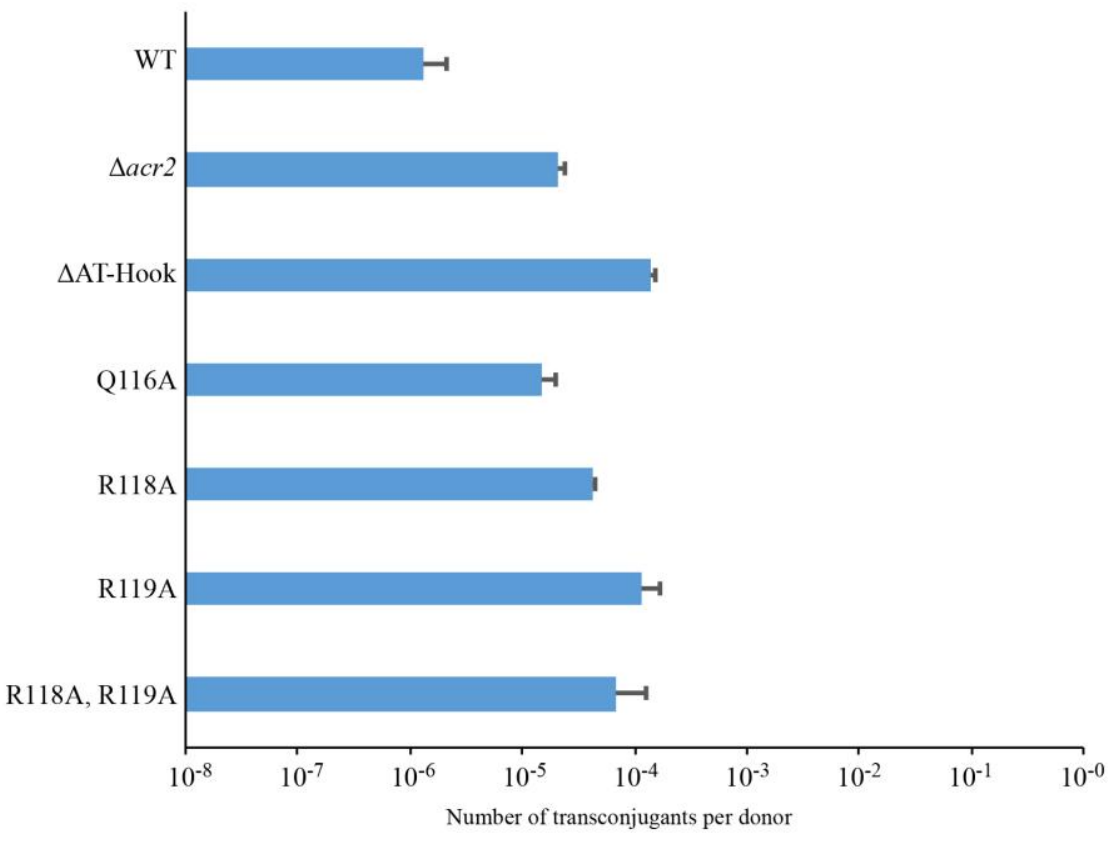

c)

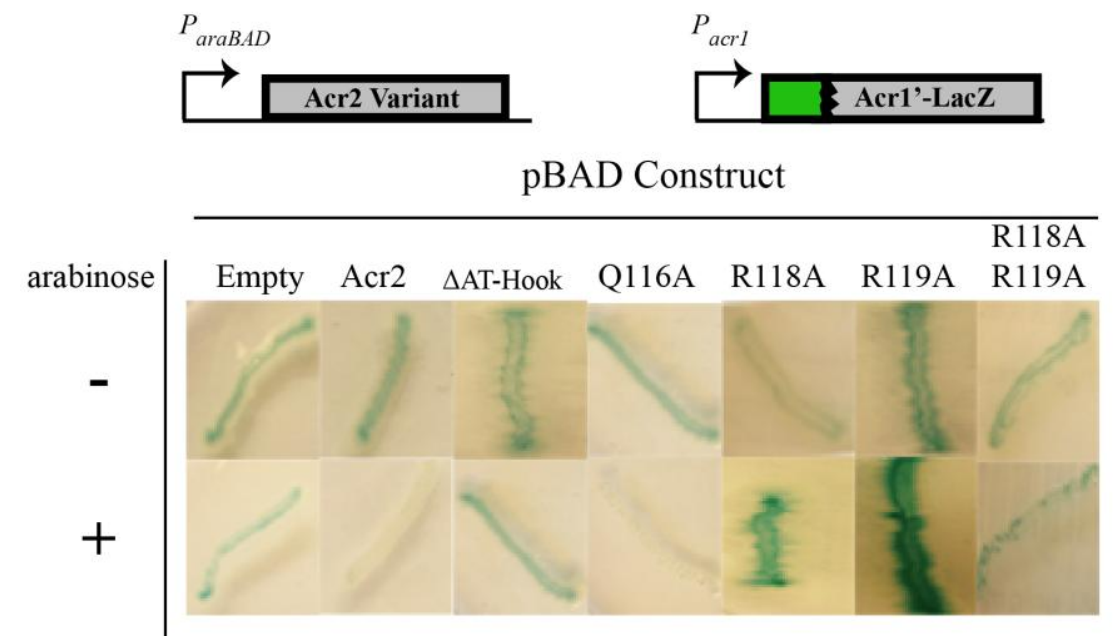




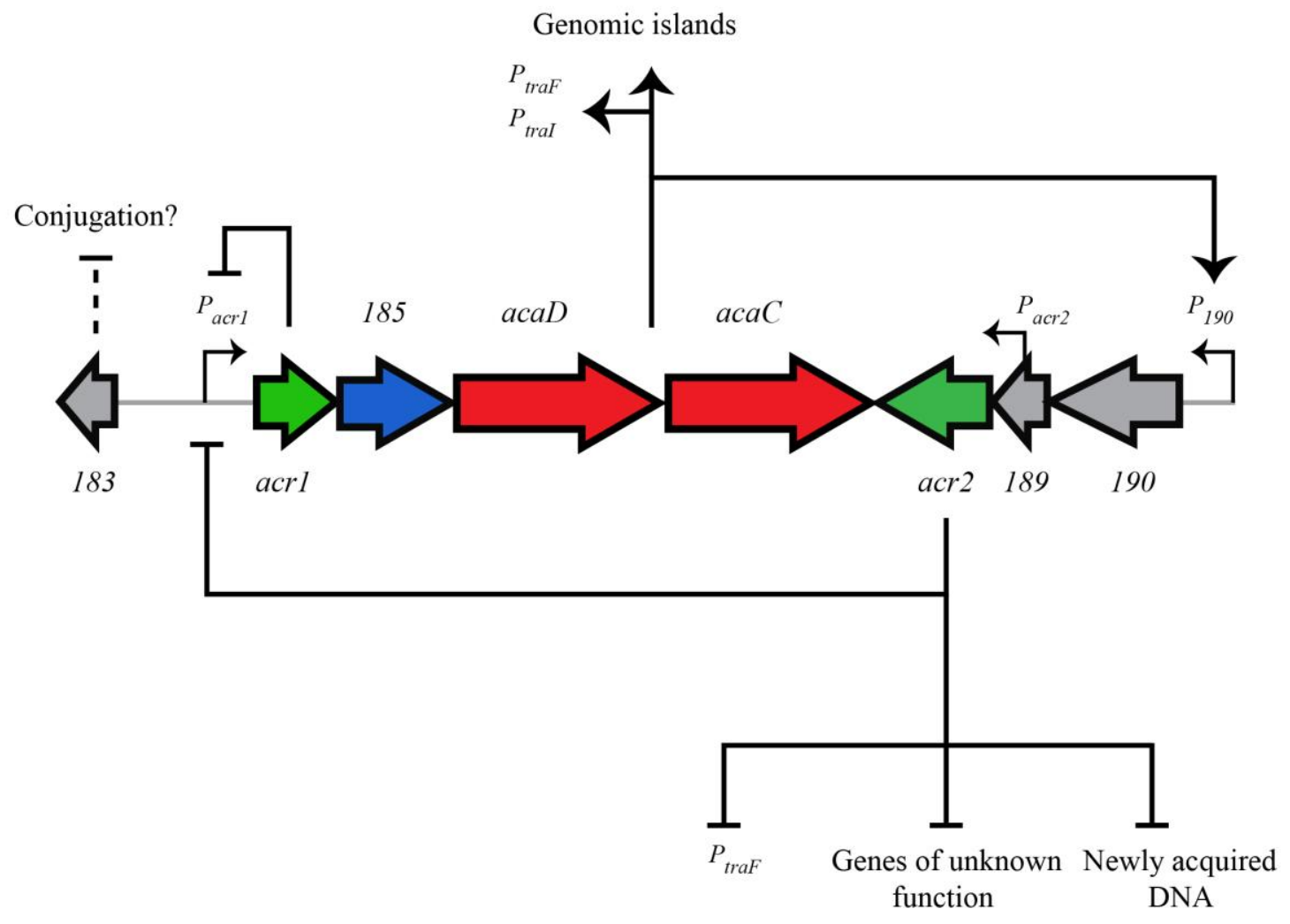


Table 1. Strains and plasmids used in this study.

\begin{tabular}{|c|c|c|}
\hline Strain or Plasmid & Characteristics & Source \\
\hline E. coli $\mathrm{DH} 10 \mathrm{~B}$ & Rif $^{R}$ strain used as a conjugation recipient & $(25)$ \\
\hline E. coli $\mathrm{MC} 4100$ & lac ${ }^{-}$strain used for observing LacZ fusion activity & $\begin{array}{c}\text { ATCC\# } \\
35695 \\
\text { Jeff }\end{array}$ \\
\hline E. coli K12 MG1655 & Model E. coli strain & $\begin{array}{l}\text { Gralnick, } \\
\text { University of } \\
\text { Minnesota }\end{array}$ \\
\hline E. coli DY331 & E. coli with stable prophage that expresses beta-gam-exo & $\begin{array}{c}\text { Don Court, } \\
\text { NIH } \\
\text { Jeff }\end{array}$ \\
\hline E. coli WM3064 & DAP auxotroph & $\begin{array}{l}\text { Gralnick, } \\
\text { University of } \\
\text { Minnesota }\end{array}$ \\
\hline E. coli WM3064nalR & nal $^{\mathrm{R}}$ mutant of WM3064 & This work \\
\hline E. coli AR060302 & Wild type host of pAR060302 & $(2)$ \\
\hline pAR060302 & IncA/C plasmid, FloR, CmR, & (2) \\
\hline pARK01 & pAR060302 derivative carrying deletion of $t e t A$ and $b l a_{\mathrm{CMY}-2}$ & This work \\
\hline pARK01-01 & pARK01 carrying deletion of orf183 & This work \\
\hline pARK01-02 & pARK01 carrying deletion of $a c r 1$ & This work \\
\hline pARK01-03 & pARK01 carrying deletion of $a c a D C$ & This work \\
\hline pARK01-04 & pARK01 carrying deletion of $a c r 2$ & This work \\
\hline pARK01-05 & pARK01 carrying lacZ fusion of the first 4 codons of $a c r l$ and $l a c Z$ and a deletion of $a c r 2$ & This work \\
\hline pARK01-06 & pARK01 carrying the Acr $2 \Delta$ AThook mutation & This work \\
\hline pARK01-07 & pARK01 carrying the Acr2(Q116A) mutation & This work \\
\hline pARK01-08 & pARK01 carrying the Acr2(R118A) mutation & This work \\
\hline pARK01-09 & pARK01 carrying the Acr2(R119A) mutation & This work \\
\hline pARK01-10 & pARK01 carrying the Acr2(R118A and R119A) mutation & This work \\
\hline pBBRLux & Plasmid carrying a promoterless lux operon; $\mathrm{Cm}^{\mathrm{R}}$ & Fitnat Yildiz, \\
\hline
\end{tabular}




pLux
pLuxFloR
pLuxTraI
pLuxTraF
pLux190
pBAD22
pB183
pBacr2
pBacaDC
pBacr2 AThook
pBacr2Q116A
pBacr2Q116A
pBacr2R119A
pBacr2R118A,R119A
pCP20
pSIM5-tet
pKD4
pKD45

pBBRLux with tetRA in place of cat

pLux with floR promoter cloned in between SpeI and BamHI sites pLux with traI promoter cloned in between SpeI and BamHI sites pLux with traF promoter cloned in between SpeI and BamHI sites pLux with orf190 promoter cloned in between SpeI and BamHI sites arabinose inducible vector, $\mathrm{Amp}^{\mathrm{R}}$ pBAD22 with orf183 cloned pBAD22 with acr2 cloned pBAD22 with $a c a D C$ cloned pBAD22 with acr2 $\triangle A$ Thook cloned pBAD22 with acr2Q116A cloned pBAD22 with acr2Q116A cloned pBAD22 with acr2R119A cloned pBAD22 with acr2R118A,R119A cloned plasmid expressing FLP recombinase, Amp ${ }^{\mathrm{R}}$, ts rep plasmid expressing beta-gam-exo used for recombineering, tet ${ }^{\mathrm{R}}$ plasmid carring FRT-neo-FRT cassette, $\mathrm{Kan}^{\mathrm{R}}, \mathrm{Amp}^{\mathrm{R}}$ plasmid carrying $n e o-c c d B$ cassette, R6K ori
UC Santa

Cruz

This work

This work

This work

This work

This work

This work

This work

This work

This work

This work

This work

This work

This work 
Table 2. Oligonucleotides used in this study.

\begin{tabular}{|c|c|}
\hline Name & Sequence \\
\hline pARdeltaTet-fw & CCGGCATTCGCTGCGCTTATGGCAGAGCAGGGAAAGGAATTGCCGGGCTAGAGCCTGACATTTATATTCC \\
\hline pARdeltaTet-rv & GGCTGCAACTTTGTCATGCTTGACACTTTATCACTGATAAACATAATATGGTCCCGCTCAGAAGAACTC \\
\hline deltaTetRepairOligo & CTTATGGCAGAGCAGGGAAAGGAATTGCCGGGCTACATATTATGTTTATCAGTGATAAAGTGTCAAGCAT \\
\hline pARdeltaBlaCMY2-fw & CTGACGGGCCCGGACACCTTTTTGCTTTTAATTACGGAACTGATTTCATGGAGCCTGACATTTATATTCC \\
\hline pARdeltaBlaCMY2-rv & AAAAAAGAGAAAGAAAGGAGGCCCAATATCCTGGGCCTCATCGTCAGTTAGTCCCGCTCAGAAGAACTC \\
\hline deltaCMYrprOligo & ACCTTTTTGCTTTTAATTACGGAACTGATTTCATGTAACTGACGATGAGGCCCAGGATATTGGGCCTCCT \\
\hline 183_KOchk-F & TCGACGGAAGCTGGAGACCGT \\
\hline 183_KOchk-R & TGATGCCGTGGTAAACTGGAGGT \\
\hline 183_koCHK-F & CCGCGCAACGCGGATAAAGC \\
\hline 183_koCHK-R & GCTGGCTCCCTTCGGCGTTT \\
\hline pBAD22_orf183-rv & ATTCCCAGAAGCACCATTCCCAGCAGAAGAATATTGACCACATGTTTCATGGTGAATTCCTCCTGCTAG \\
\hline pBAD22_orf183-fw & ATTCCTATGATTTTGACCAGCGCTTCCATATTGGAGCTGGAGACGAATAAGTACCCGGGGATCCTCTAG \\
\hline pbadseq-2 & GGCTGAAAATCTTCTCT \\
\hline pbadseq-1 & CTGTTTCTCCATACCCGTT \\
\hline acr1_KO-F & TGTATGGCTAACAACGCAGTTTAAAGGGTGGCAAACAATGGTGTAGGCTGGAGCTGCTTC \\
\hline acr1_KO-R & GCCGCAGACAGAACTAGCGCCTTGGCTTTGTTCTTCATCAATGGGAATTAGCCATGGTCC \\
\hline acr1_KOchk-F & ACAACGCAGTTTAAAGGGTGGCA \\
\hline acr1_KOchk-R & GCCGCAGACAGAACTAGCGCC \\
\hline acaDC_KO-F & ATCTATCGCAACCTTCGTGATTTGTGAGGGGGGCGGAATGGTGTAGGCTGGAGCTGCTTC \\
\hline acaDC_KO-R & GGGCGCTCATCTTCTGGTCCGAAATGTCATAGTCTACTCAATGGGAATTAGCCATGGTCC \\
\hline acaDC_KOchk-F & GCCGCTATCACGCCTGGGAA \\
\hline acaDC_KOchk-R & GGGCGCTCATCTTCTGGTCCG \\
\hline pBAD22_acaDC-rv & TGTCGAGCTGTAACCCAGCGACCCAATGTACCAGAGTTGCCAATGTTCATGGTGAATTCCTCCTGCTAG \\
\hline pBAD22_acaDC-fw & TATTGAAAAAACTGCAACAGTCTCTACAGGGACGTGGGAGGTGGAGATGAGGCTGTTTTGGCGGATGAGA \\
\hline pBBR-F & CGCGCGTAATACGACTCACT \\
\hline pBBR-R & TCGGGAAAGATTTCAACCTG \\
\hline
\end{tabular}


cat_frt-tet-frt-fw cat_frt-tet-frt-rv BamHI-190p-rv SpeI-190p-fw BamHI-floRp-rv SpeI-floRp-fw BamHI-traFp-rv SpeI-traFp-fw BamHI-traIp-rv SpeI-traIp-fw acr2_ko-F acr2_ko-R acr2_chk-F acr2_chk-R

pBAD22_acr2_6xhis-fw

pBAD22_acr2-rv

acr1-EMSA-F

acr1-EMSA-R

floRp-rv

floRp-fw

delATHOOKAcr2-kanccdB-fw delATHOOKAcr2-kanccdB-rv

delATHOOK-repair

Acr2Q116A

Acr2R118A
GACCGTTCAGCTGGATATTACGGCCTTTTTAAAGACCGTAGAATTCGAGCTCGGTACCCG ATTGGCTGAGACGAAAAACATATTCTCAATAAACCCTTTAGCTATGACCATGATTACGCC GGATCCATAACATGAAATCCTCCAAAGATT

GATACTAGTTGCTGGAGGGCAAGCGGTTC

GGATCCATAACATGACGAATCAACCCTCG

GATACTAGTAAAGATAATCGGATAAAATG

GGATCCATAACACGTATTTTCCCATGCTCG

GATACTAGTGGACACGACCAAATAGTTTG

GGATCCATAACATGTAGGTTGACCATATTC

GATACTAGTTCGTTCCTCATAAAAAATTG

AGAAGATGAGCGCCCAAACTTTGCGGCGCTCATTTTTTTAGTGTAGGCTGGAGCTGCTTC GATTCACTTAAAGGAAAACTGATGGGCTCCGTATGACATGATGGGAATTAGCCATGGTCC AGGAAGGCATGGTGGTGGGGA

ATTCGCCAGTGCAGACTGACGC

AGCTGTCGAGCTGGAGCGCTACCGTATCCCACAGAAGAAGCATCACCATCA CCATCACTAAGGCTGTTTTGGCGGATGAGA

CAGCCGCTGATAGCGTAGAGAACTCCTCGTGGTCTTTCATGGTGAATTCCTCCTGCTAG CCСТAAAATCACTTATACC

CAATTGGCATTTATCCATTG

ACATGACGAATCAACCCTCG

AAAGATAATCGGATAAAATG

CTCCAGCTCGACAGCTCCCAACCCCTTGAAAGCATCCGGGGTCCCGCTCAGAAGAACTC ATTCAAAAGACGGAGTTTCGTGGAGTGGGCAAGGACGTCGGAGCCTGACATTTATATTCC

CGCTCCAGCTCGACAGCTCCCAACCCCTTGAAAGCCCCACTCCACGAAACTC CGTCTTTTGAATATTTAG

CTAAATATTCAAAAGACGGAGTTTCGTGGAGTGGGGCGGGACGTC GCCCGGATGCTTTCAAGGGGTTGGGAGC

AATATTCAAAAGACGGAGTTTCGTGGAGTGGGCAAGGAGCGCGCC CGGATGCTTTCAAGGGGTTGGGAGCTGT 
Acr2R118A-R119A

Acr2R119A

deltalacAY-fw

deltalacAY-rv

acr1-lac-rv

acr1-lac1-fw
AATATTCAAAAGACGGAGTTTCGTGGAGTGGGCAAGGA GCGGCGCCGGATGCTTTCAAGGGGTTGGGAGCTGTCGA

ATTCAAAAGACGGAGTTTCGTGGAGTGGGCAAGGACGTG CGCCGGATGCTTTCAAGGGGTTGGGAGCTGTCGA

GCCTGATAAGCGCAGCGTATCAGGCAATTTTTATAATTTAGTGTAGGCTGGAGCTGCTTC

CAGGCCATGTCTGCCCGTATTTCGCGTAAGGAAATCCATTATGGGAATTAGCCATGGTCC TTTGGGCGCTCATCTTCTGGTCCGAAATGTCATAGTCTACCGTGTAGGCTGGAGCTGCTT

AACAACGCAGTTTAAAGGGTGGCAAACAATGGATAAATGCCCCGTCGTTTTACAACGTCG 